Volume: 11

Issue: 01

Years: 2021

\section{Original Article \\ Differences \\ Premature \\ Intervention \\ Infant Oralmotor (PIOMI) And \\ Oromotor Stimulation (OMS) To Readiness Oral Feeding}

\author{
Sumarni*, Titin Sutini ${ }^{1}$, Rohadi Hariyanto ${ }^{1}$ \\ *Student of Nursing Master Program, University of \\ Muhammadiyah Jakarta, Indonesia \\ ${ }^{1}$ Nursing Master Program, University of Muhammadiyah \\ Jakarta, Indonesia \\ Email Corespondent : sumarnisopian180@gmail.com
}

\section{open 2 access}

Editor: Kresna

Received: 24 Jan 2021

Accepted: 2 Mar 2021

Published: 31 Mar 2021

Available Article :

10.33221/jiiki.v11i01.943

Copyright : (C2021 This article has open access and is distributable under the terms of the Creative Commons Attribution License, which permits unrestricted use, distribution and reproduction in any medium, provided the name of the author and the original source are included. This work is licensed under a Creative Commons Attribution-Share Alike 4.0 International License

Conflict of interest statement : declare that this research is independent of the conflict of interest of both individuals and organizations

Funding : This study is personal funding

\begin{abstract}
Introduction: Premature birth is one of the biggest contributors to neonatal mortality and morbidity. It is difficult for premature infants to adapt to life outside the womb due to the immaturity of various organ systems, one of which is the suction reflex relevant to the readiness to oral feeding. Difficulty in oral feeding due to the weakness of sucking is a concern since it often delays the discharge of the infants from the hospital, negatively affects the relationship between mother and infants, and potentially causes eating disorders in children. Some of these reasons are the basis for early intervention to improve oral feeding ability. Interventions that can be carried out are PIOMI and OMS interventions

Objectives: This research aimed at identifying the differences in effectiveness between PIOMI and OMS with respect to the readiness of premature infants to oral feeding in the perinatology division of KMC Hospital, Luragung

Methods: The method used was a quasi-experimental research with pretest and posttest using a number of samples $(\mathrm{N})=32$ respondents divided into two intervention groups respectively consisting of 16 respondents

Results: The results indicated that PIOMI $(\Delta=9.0, \mathrm{p}$-value $=$ $0.000)$ and $\operatorname{OMS}(\Delta=7.3$, p-value $=0.000)$ had an effect on the readiness of premature infants to oral feeding. PIOMI intervention had a greater difference that consequently, it was more effective than OMS intervention. The confounding factors affecting the readiness of premature infants to oral feeding were gestational age and body weight, while chronological age did not affect Conclusion: Based on the research results, it was suggested that nurses can use PIOMI intervention to make premature infants ready for oral feeding
\end{abstract}

Keywords: premature, oral stimulation, readiness to oral feeding

\title{
Introduction
}

Premature infants are neonatal born alive before the 37 th week of gestation age. ${ }^{1}$ The number of preterm births is estimated at 15 million each year. Indonesia is in the top 10 of 184 countries with a high incidence of prematurity, namely 15.5 preterm births per 100 live births. ${ }^{1}$ The proportion of premature births in Indonesia in 2018 was $29.5 \%$. $^{2}$ 
In West Java Province, the proportion of preterm births is $23.5 \%$ and the highest number is in Kuningan Regency at $25.7 \% .^{3}$ It is difficult for premature infants to adapt to life outside the womb due to the immaturity of various organ systems, one of which is the suction reflex relevant to the readiness to oral feeding. Underdevelopment of the sucking reflex in premature infants is characterized by the emergence of oral feeding problems which will cause delays in direct feeding, low body weight, and dehydration during the early postnatal weeks. ${ }^{4}$ Difficulty in oral feeding due to the weakness of sucking is a concern since it often delays the discharge of the infants from hospital, negatively affects the relationship between mother and infants and potentially causes eating disorders in children. Some of these reasons are the basis for early intervention to improve oral feeding ability. ${ }^{4}$

Oral stimulation can be used to improve oral feeding ability in premature infants. The therapy that can be used is the Premature Infant Oral Motor Intervention (PIOMI). PIOMI is an intervention in the oral area that can increase muscle contraction and strength in premature infants in 8 movements within 5 minutes. ${ }^{5}$ Apart from PIOMI, there are other ways that can be used to stimulate oral feeding ability in premature infants, that was Oromotor Stimulation (OMS). OMS is sensory stimulation of the mouth area and respiratory muscles which affects the sucking and swallowing mechanism. OMS can be done in 10 movements for 15 minutes every day for 7 consecutive days. ${ }^{6}$ The conservation theory developed by Myra Estrina Levine and known as the Levine's Conservation Model can be implemented by nurses in providing nursing care to premature infants. It is hoped that the increase in the suction reflex will increase the intake of nutrients orally which is a source of energy and can be used for optimal growth and development. Based on the description above, the researchers are interested in conducting research on the differences in the effectiveness between Premature Infant Oro Motor Intervention (PIOMI) and Oromotor Stimulation (OMS) with respect to the readiness of premature infants to oral feeding.

\section{Methods}

This study used a Quasi Experiment design with pre test and post test. Respondents in this study were 32 who were divided into two groups that was PIOMI and OMS group, namely 16 respondents each. The sampling used purposive sampling technique with inclusion criteria : born with a gestational age $<37$ weeks, have stable hemodynamics, are allowed by parents to be respondents and have poor and good enough drinking readiness levels (POFRAS score <31). The research instrument used the POFRAS (Premature Oral Feeding Readiness Assessment Skill). This scale has been tested for the validity and reliability of 60 stable preterm infants. The results of the validity test show an accuracy of $74.38 \%$ and a specification of $75.68 \%$ where this rating scale is valid for use. ${ }^{7}$ The data analysis in this study was carried out using the central tendency (univariate), and the Wilcoxon and Mann Whitney (bivariate) tests.

\section{Results}

Table 1 Characteristics premature infants and readiness oral feeding on PIOMI dan OMS group

\begin{tabular}{lllll}
\hline Variable & Mean & Median & SD & Min - Max \\
Gestational age & & & & \\
$\quad$ PIOMI group & 31,8 & 31,5 & 2,4 & $29-35$ \\
$\quad$ OMS group & 32,4 & 33,0 & 2,1 & $29-35$ \\
\hline $\begin{array}{l}\text { Chronological age } \\
\quad \text { IOMI group }\end{array}$ & 1,2 & 1,0 & 0,4 & $1-2$ \\
OMS group & 1,2 & 1,0 & 0,4 & $1-2$ \\
\hline Body weight & & & & \\
$\quad$ PIOMI group & 1767,2 & 1642,5 & 460,3 & $1150-2355$ \\
OMS group & 1850,6 & 1947,5 & 379,3 & $1200-2460$ \\
\hline
\end{tabular}


Differences Effectiveness Premature Infant Oralmotor Intervention (PIOMI), and...

\begin{tabular}{lllll}
\hline $\begin{array}{l}\text { Readiness to oral feeding in PIOMI group } \\
\text { Before }\end{array}$ & & & & \\
$\quad$ & & & & \\
$\quad$ after & 31,8 & 20,5 & 4,6 & $18,00-29,00$ \\
& 31,0 & 2,9 & $28,00-36,00$ \\
\hline Readiness to oral feeding in OMS group & & & & \\
$\quad$ Before & & & & \\
$\quad$ after & 26,1 & 27,0 & 2,8 & $20,00-29,00$ \\
& 33,4 & 33,5 & 2,4 & $30,00-36,00$ \\
\hline
\end{tabular}

Table 1 shows the mean gestational age in the PIOMI group was younger than the OMS group. The mean chronological age was no difference between the PIOMI and OMS intervention groups. The mean - body weight of infants in the PIOMI group was lower than in the OMS group. The strength of oral feeding in the PIOMI group before the intervention had an average value of 22.8 and increased after the intervention the average to 31.9. Whereas in the OMS group the average readiness to oral feeding before the intervention was 26.1 and after the intervention was 33.4 .

Table 2. Differences in readiness oral feeding of premature infants before and after given PIOMI and OMS intervention

\begin{tabular}{lccc}
\hline Variable & Mean & SD & p value \\
\hline $\begin{array}{l}\text { Readiness oral feeding value } \\
\text { PIOMI group }\end{array}$ & & \\
Before & 22,8 & 4,6 & 0,000 \\
After & 31,8 & 2,9 & \\
Difference & 9,0 & & \\
OMS group & & & 0,000 \\
Sebelum & 26,1 & 2,8 & \\
Sesudah & 33,4 & 2,4 & \\
Difference & 7,3 & & \\
\hline
\end{tabular}

Table 2 shows that in the PIOMI group there was an increase in the level of readiness oral feeding before and after the intervention was given with a difference of 9.0. The statistical test results obtained $\mathrm{p}$ value $=0.000(<0.05)$. Table 2 also shows that in the OMS group there was also an increase in readiness oral feeding and according to intervention given a difference of 7.3 and $p$ value $=0.000(<0.05)$. It can be concluded that there are differences in the level of readiness to oral feeding in premature infants before and after being given OMS intervention.

Table 3. Differences in the effectiveness of PIOMI and OMS on readiness oral feeding

\begin{tabular}{llll}
\hline Variable & Group & Mean difference & p value \\
\hline Readiness oral feeding & PIOMI & 13,9 & \multirow{2}{*}{0,107} \\
& OMS & 19,1 & \\
\hline
\end{tabular}

Table 3 shows that there is no significant difference between the group of respondents who received PIOMI and OMS intervention with $\mathrm{p}$ value $=0.107(>0.05)$. It can be concluded that there is no significant difference between the group of respondents who received PIOMI and OMS intervention. The strength of oral feeding in the PIOMI group before the intervention had an average value of 22.8 and after the intervention the average increased to 31.9. Whereas in the OMS group the average readiness to oral feeding before the intervention was 26.1 and after the intervention was 33.4.

\section{Discussion}

The mean gestational age of respondents in the PIOMI group was 31.8 weeks and the 
Differences Effectiveness Premature Infant Oralmotor Intervention (PIOMI), and...

OMS group was 32.4 weeks. As previously explained, the ability to swallow in infants already exists at 32 weeks gestation age and the ability to suck begins to develop at 34 weeks gestation age. Synchronization of the ability to suck and swallow develops well at 36-38 weeks gestation age. ${ }^{8}$ So it can be concluded that all of the respondents in this study did not have good oral feeding readiness. The smaller the gestational age, the weaker the ability to suck and swallow. The average chronological age of the research respondents in both the PIOMI and OMS groups was 1.2 days. Infants aged less than one week usually experience delays in oral feeding. ${ }^{9}$ Chronological age is associated with readiness oral feeding in premature infants because this is related to the stimuli given during treatment (development care) carried out by nurses to improve the ability to suck and swallow. In this study, most of the respondents had a one day chronological age so that there was not much stimulus provided by the nurses. The average body weight of infants in the PIOMI group was 1767.2 grams and the OMS group was 1850.6 grams. The majority of premature infants have a birth weight of less than 2500 grams and the suction reflex is also influenced by birth weight. ${ }^{10}$ Infants who have large body weight will try harder to meet the nutritional needs of their body than small body weight, so this will affect the suction reflex. In this study, all respondents had body weigh $<2500$ grams so that the suction reflex and readiness oral feeding are not good enough. ${ }^{11}$

The results showed that there were differences in the level of readiness oral feeding before and after being given PIOMI intervention ( $\mathrm{p}$ value $=0.000$ ) with a difference of $=9.0$. PIOMI is an intervention in the oral area that can increase muscle contraction and strength in premature infants. PIOMI was developed by Brenda S. Lessen, PhD, RN from Illinois Wesleyan University, Bloomington. PIOMI consists of 8 steps that are carried out in 5 minutes. ${ }^{5}$ In this study, respondents who previously had poor and quite good readiness oral feeding levels, after the PIOMI intervention for seven days showed an increase for the better. The post-intervention assessment was carried out on the seventh day using the same rating scale and the difference was quite large 9.0. The results showed that there was a difference in the level of readiness oral feeding before and after being given OMS intervention $(\mathrm{p}$ value $=0.000)$ with a difference $=$ 7.3. OMS (oromotor stimulation) is sensory stimulation of the mouth area and respiratory muscles which affects the mechanism of sucking and swallowing. ${ }^{12}$ OMS can be done for 15 minutes. The results showed that respondents in the OMS group experienced an increase in readiness oral feeding between before and after the intervention with a difference of 7.3. This shows positive results and is in line with previous studies.

The results of the Man Whitney test conducted on differences in the effectiveness of PIOMI and OMS interventions on oral feeding readiness for premature infants found no significant difference between the PIOMI and OMS intervention groups, but the results of the Wilcoxon test showed that the PIOMI intervention group had a greater difference. Compared to the OMS intervention group, it can be concluded that the PIOMI intervention is considered more effective in increasing oral feeding readiness in preterm infants than the OMS intervention. The administration of PIOMI intervention is more effective in increasing readiness oral feeding because researchers assume that PIOMI movements are simpler and are carried out in a shorter time so that premature infants are not easy to stress, because basically one of the principles of preterm baby care is reducing stress and minimal handling. ${ }^{13}$ Providing stimulation needs to be done but still must pay attention to the principles of care for premature infants.

The provision of PIOMI intervention can improve all subsystems in the organization of neonatal behavior which include autonomy, motor, awareness, interaction of attention and selfregulation so that it will have an impact on the process of maturation, integration, synchronization, and physiological stability. ${ }^{14}$ The PIOMI movement carried out by massage will increase blood flow and cause vasodilation of active muscles so that oxygen and other nutrients in the tissue increase in number and cardiac output will increase. In addition, oral 
stimulation with massage on the tone of the vagus nerve will also increase the absorption of gastrin and insulin, thereby better absorption of food, and cause the infants to be hungry quickly which will stimulate the suction reflex. ${ }^{15}$

\section{Conclusion}

Based on the research results, it can be concluded that PIOMI intervention is more effective in increasing readiness to oral feeding in premature infants than OMS intervention.

\section{Conlict of Interest Declaration}

declare that this research is independent of the conflict of interest of both individuals and organizations

\section{Acknlowledge}

Thank you to all partisipant in this study

\section{Funding}

This study is personal funding

\section{References}

1. WHO. Infants Mortality Rate. Des 3, 2019, 2012. http://www.who.int/mediacentre

2. Indonesian Ministry of Health. Riskesdas National Report. Jakarta; 2018. http://www.labdata.litbang.depkes.go.id

3. West Java Provincial Health Office. Health profile of West Java Province. Bandung; 2016. http://www.dinkes.jabarprov.go.id

4. Fucile, Sandra, Erika Gisel, and Chantal Lau. "Oral stimulation accelerates the transition from tube to oral feeding in preterm infants." The Journal of pediatrics 141.2 (2002): 230-236.

5. Lessen, Brenda S. "Effect of the premature infant oral motor intervention on feeding progression and length of stay in preterm infants." Advances in Neonatal care 11.2 (2011): 129-139.

6. Greene, Zelda, Colm PF O'Donnell, and Margaret Walshe. "Oral stimulation techniques in preterm infantsInternational research challenges." Journal of Neonatal Nursing 19.4 (2013): 168-174.

7. Fujinaga, Cristina Ide, et al. "Clinical validation of the preterm oral feeding readiness assessment scale." Revista latino-americana de enfermagem 21.spe (2013): 140-145.

8. Hockenberry, Marilyn J., and David Wilson. Wong's essentials of pediatric nursing9: Wong's essentials of pediatric nursing. Elsevier Health Sciences, 2013.

9. Fawcett, Jacqueline, and Susan Desanto-Madeya. Contemporary nursing knowledge: Analysis and evaluation of nursing models and theories. FA Davis, 2016.

10. Lau, Chantal. "Development of suck and swallow mechanisms in infants." Annals of Nutrition and Metabolism 66.Suppl. 5 (2015): 7-14.

11. Berkowitz, A., Papiernik, D. Lecture notes patofisiologi clinic. Tangerang selatan : Binarupa, 2010.

12. Lyu, Tian-chan, et al. "The effect of an early oral stimulation program on oral feeding of preterm infants." International journal of nursing sciences 1.1 (2014): 42-47.

13. Ghomi, Hadiseh, et al. "The effects of premature infant oral motor intervention (PIOMI) on oral feeding of preterm infants: A randomized clinical trial." International journal of pediatric otorhinolaryngology 120 (2019): 202-209.

14. Riordan, Jan, and Karen Wambach, eds. Breastfeeding and human lactation. Jones \& Bartlett Learning, 2010.

15. Purnama, Agus. " Implementation of Atraumatic Care with Medical Play on the Anxiety Response of Preschool Children who are Hospitalized in Children's Inpatient Rooms." Indonesian Nursing Scientif journal 8.04 (2018): 516-521. 
